Research Article

\title{
Phytochemicals, Nutritional Value, Antioxidant, and Anticoagulant Activity of Lactuca sativa L. Leaves and Stems
}

Hanin Nafed Mughrbi ${ }^{*}{ }^{*}$
Abdurazag Abdussalam Auzi ${ }^{1}$
Hamza Maghrbi ${ }^{2}$
1Department of Pharmacognosy,
Faculty of Pharmacy, University of
Tripoli, Tripoli, Libya
2Medical Analysis Laboratory, National
Centre for Diabetes and Endocrinology,
Tripoli, Libya
*email: haneenafeth@yahoo.com
Keywords:
Activated Partial Thromboplastin Time
Anticoagulants
DPPH
Lactuca sativa
Prothrombin Time

\begin{abstract}
The main ingredient in the daily salad dish is the leaves of Lactuca sativa, while the stems are usually discarded and not eaten. This study was conducted to compare the stems and leaves of two selected $L$. sativa varieties (L. sativa var. longifolia $L$. and L. sativa var. capitata L.) related to the preliminary phytochemical investigation, nutrient content, DPPH assay, and in vitro anticoagulant activity by determination of prothrombin time (PT) and activated partial thromboplastin time (aPTT). The findings revealed almost the same phytoconstituents in the leaves and stems of each variety, such as terpenoids, flavonoids, coumarins, and others. Exceptionally, tannins have only been detected in the leaves. Compared to the stems, the leaves of both varieties showed statistically significantly higher levels of raw protein and raw fat. For the DPPH assay, the leaves of both varieties have a statistically significantly higher antioxidant activity than the stems. The leaves and stem extract of the two selected varieties showed a significant prolongation of $\mathrm{PT}(\mathrm{P}<0.05$ vs. NS= $12: 30 \mathrm{~s})$. On the other hand, the aPTT test showed a significant increase in aPTT ( $\mathrm{P}<0.05$ vs. NS = 32:44 s) in the stem extract of both varieties, whereas there was no statistically significant increase in aPTT in the leaves of both varieties. Both parts of each variety have a diversity of phytochemicals and nutrients. The leaves of both varieties have a higher antioxidant activity than the stems. While the stems had higher anticoagulant activity than the leaves.
\end{abstract}

Received: May 10th, 2020

Accepted: June 16th 2020

Published: August 31st, 2020

(c) 2020 Hanin Nafed Mughrbi, Abdurazag Abdussalam Auzi, Hamza Maghrbi. Published by Institute for Research and Community Services Universitas Muhammadiyah Palangkaraya. This is an Open Access article under the CC-BY-SA License (http://creativecommons.org/licenses/by-sa/4.0/). DOI: https:// doi.org/10.33084/bjop.v3i3.1394

\section{INTRODUCTION}

The administration of prescribed anticoagulant medicines by patients with cardiovascular diseases is very crucial to minimize the risk of thrombosis formation and to maintain the normal blood flowability (Buttar et al., 2005). On the other hand, the serious side effects of those medicines also cause a danger of bleeding in addition to the difficulty in dose monitoring for patients been under anticoagulant therapy (Cordier \& Steenkamp, 2012). Therefore, the orientation toward the plants as a source of cheap anticoagulant drugs with minimum side effects is the desired objective of anticoagulant therapy.

One of the most used up leafy vegetables under family Asteraceae is Lactuca sativa (Alavi, 1983; Mughrbi \& Auzi, 2020), which is vernacularly known as lettuce or khas in Libya. Popularly, the major consuming part in L. sativa is the leaves; whereas, the stems are usually discarded and not eaten. Most of the researches that have been conducted on L. sativa focus only on leaves while the juicy stem has a few documented studies. The leaves of $L$. sativa are considered a valuable source of phenolic compounds (Ribas-Agusti et al., 2011) and sesquiterpene 
lactones (Michalska et al., 2009). Several biological actions of L. sativa leaves have been reported such as antioxidant scavenging activity (Zdravković et al., 2014), antiinflammatory property (Araruna \& Carlos, 2010), analgesic, antidepressant, and in vivo anticoagulant activities (Ismail \& Mirza, 2015; Ismail et al., 2017). Few studies have been carried out on the stems exactly on the stem lettuce or Chinese lettuce (L. sativa var. angustana). From the stem lettuce (Nie et al., 2017; Nie et al., 2018) have separated a sulfated heteropolysaccharide which possesses an antioxidant, a-amylase inhibitory, and immunomodulatory activities. About twenty-one sesquiterpene lactones were isolated and characterized from the stem lettuce by (Han et al., 2010), some of these compounds have revealed a significant antioxidant activity.

Research is applied to the two parts (leaf and stem) of each variety (L. sativa var. longifolia and L. sativa var. capitata) to investigate the phytochemical of methanol extracts. Also, this study aims to determine the nutritional value, in vitro antioxidant activity, and in vitro anticoagulant activity.

\section{MATERIALS AND METHODS}

\section{Plant material collection, identification, and processing}

Varieties (Romaine lettuce and iceberg lettuce) were collected from different markets in Tripoli, Libya, in November 2017. Samples were identified by Dr. Mohamed N. Abuhadra, a plant taxonomist at the Department of Botany, Faculty of Science, University of Tripoli. The varieties identified have been $L$. sativa var. longifolia L. and L. sativa var. capitata L. with voucher numbers D1 68107922 and D2 68107921, respectively. The leaves and stems of each variety were separated and washed away by distilled water. The leaves had been dried in shade for two weeks, but the stems had been dried in the oven at $40^{\circ} \mathrm{C}$ for $16-18$ hours. The dried parts were powdered using an electric grinder and stored in polyethylene sealing bags in the refrigerator at $4^{\circ} \mathrm{C}$.

\section{Extraction of phytochemicals}

The powdered leaves of $350 \mathrm{~g}$ and the powdered stems of $300 \mathrm{~g}$ of both varieties were extracted by cold maceration with a powder ratio of $10 \mathrm{~g}: 100 \mathrm{ml}$ of solvent (Bhat \& Al-Daihan, 2014). The powders were extracted twice, using 99\% methanol for four days each time, and then filtered. The filtrates were concentrated at $40^{\circ} \mathrm{C}$ under reduced pressure by rotary evaporator. The weights of the dry extracts were calculated and the extracts stored in the refrigerator at $4^{\circ} \mathrm{C}$.

\section{Preliminary phytochemical investigation}

The methanolic extracts of each part of both varieties have been subjected for the standard procedures for phytochemical screening such as carbohydrates (Singh et al., 2012; Evans, 2009), saponins (Ngbede et al., 2008), terpenoids, steroids (Mir et al., 2016), flavonoids (Bhandary et al., 2012), tannins (Edeoga et al., 2005), coumarins (Morsy, 2014), and mucilage (Banu \& Cathrine, 2015).

\section{Estimation of nutritional value}

The powder of the leaves and the stems of each variety have been analyzed according to the Association of Official Analytical Chemists (Association of Official Agricultural Chemists, 1990; Association of Official Agricultural Chemists, 2000). All the procedures were repeated in duplicate.

\section{Estimation of total ash}

Total ash was determined by the primary ignition of $4 \mathrm{~g}$ of each sample in a pre-weighed crucible until fully carbonized, and then gradually increased the temperature of the muffle furnace to $550^{\circ} \mathrm{C}$ overnight until carbon-free ash was obtained. The crucible has been weighed. The percentage of total ash has been calculated as follows: 
Total ash $(\%)=($ Weight of ash/Weight of sample $) \times 100$

\section{Estimation of moisture content}

The moisture content was determined by the drying method using the oven. As much as $5 \mathrm{~g}$ of dry powder of sample was placed in previously weighed, dry, and clean petri dish for each sample, and then the dish dried in the oven at $105^{\circ} \mathrm{C}$ for $3-4$ hours until reaching the constant weight. The percent of moisture content was calculated using the following equation:

Moisture content $(\%)=\left(\mathrm{Wt}_{1}-\mathrm{Wt}_{2} / \mathrm{Wt}_{3}\right) \times 100$

$\mathrm{Wt}_{1}=$ Weight of petri dish and sample before drying

$\mathrm{Wt}_{2}=$ Weight of petri dish and sample after drying

$\mathrm{Wt}_{3}=$ Weight of sample.

\section{Estimation of crude protein}

The Crude protein was determined using the Kjeldahl method. As much as $1 \mathrm{~g}$ of each L. sativa powder was placed in a digestion flask containing $3 \mathrm{~g}$ of Kjeldahl catalyst and $12 \mathrm{ml}$ of concentrated $\mathrm{H}_{2} \mathrm{SO}_{4}$ and was digested for an hour. The flask was then transferred to the distillation unit with $25 \mathrm{ml}$ of $40 \% \mathrm{NaOH}$ for ammonia release. The flask content was titrated with $0.1 \mathrm{~N} \mathrm{HCl}$ in the presence of $25 \mathrm{ml}$ of $4 \%$ boric acid with two drops of bromocresol green (BCG) and methyl red $5: 1$. The protein percentage was calculated as follows:

Crude protein $(\%)=($ Sample volume - blank volume $) \mathrm{x}$ $\mathrm{N} \times 14.007 \times 6.25 \times 100 /$ Sample weight $(\mathrm{mg})$

$\mathrm{N}=$ Normality of standard $\mathrm{HCl}$

Estimation of crude fat

As much as $100 \mathrm{ml}$ of petroleum ether $\left(40-60^{\circ} \mathrm{C}\right)$ was poured in the pre-weighed cup. About $3 \mathrm{~g}$ of each sample was transferred into extraction thimble. The extraction process has proceeded in the automated Soxhlet system by two steps, extraction step an hour followed by rinsing step for 30 minutes. Then the cup was dried in the oven at $105^{\circ} \mathrm{C}$ and weighed. The percentage of crude fat was calculated using the following formula:

\section{Crude fat $(\%)=($ Weight of extracted fat/Weight of sample) $\times 100$}

\section{In vitro analysis of antioxidant activity}

The quantitative DPPH scavenging activity was determined following Kumarasamy et al. (2007) and Kumar et al. (2014) protocols with little modifications. The methanolic solution of DPPH with concentration (80 $\mu \mathrm{g} / \mathrm{ml})$ was prepared. The stock solutions $(10 \mathrm{mg} / \mathrm{ml})$ of dry methanolic extracts of $L$. sativa were serially diluted to obtain the following concentrations $(5,2.5,1.25,0.625$, 0.31 , and $0.15 \mathrm{mg} / \mathrm{ml}$ ). About $1 \mathrm{ml}$ of each diluted solution was mixed with $1 \mathrm{ml}$ of DPPH solution and left for 30 minutes in a dark place for complete reaction. After 30 minutes the UV absorbance was recorded by spectrophotometer at $517 \mathrm{~nm}$. L-ascorbic acid was used as a positive control. The mixture of $1 \mathrm{ml} \mathrm{DPPH}$ and $1 \mathrm{ml}$ methanol was utilized as a negative control. The experiment for each extract was measured in duplicate. The results were expressed as a percentage of radical scavenging activity and were calculated by the formula as described by Najafabad \& Jamei (2014). The $\mathrm{IC}_{50}$ value was calculated from the linear regression equation, which is obtained from the plotted graph of \% inhibition of DPPH against the different concentrations of extracts.

\section{In vitro assay of anticoagulant activity}

The study pursues (Cordier et al., 2011; Chen et al., 2014) protocols for assaying the in vitro anticoagulant action of extracts with suitable amendments.

\section{Volunteers recruitment}

Four healthy volunteers of both genders (ages 25-37 years). They were asked to ensure that they had not any previous history for CVDs or medicines administration such as anticoagulant, antiplatelet, and vitamin supplement, etc. Before blood collection, informed consent has been acquired and signed via all volunteers for their participation in this study. All volunteers have 
subjected to twice measurements of routine PT and aPTT tests to ascertain the normality of the collected blood.

\section{Volunteers recruitment}

Four healthy volunteers of both genders (ages 25-37 years). They were asked to ensure that they had not any previous history for CVDs or medicines administration such as anticoagulant, antiplatelet, and vitamin supplement, etc. Before blood collection, informed consent has been acquired and signed via all volunteers for their participation in this study. All volunteers have subjected to twice measurements of routine PT and aPTT tests to ascertain the normality of the collected blood.

\section{Blood collection, plasma preparation, and extracts preparation}

Blood was collected by venipuncture of each volunteer and collected separately into (3.2\%) sodium citrate (9 : 1 v/v, blood : anticoagulant sodium citrate) vacuum tube and mixed well. Immediately, the collected blood was centrifuged at $4000 \mathrm{rpm}$ for 10 minutes to obtain PPP (platelet-poor plasma). Working solutions for each extract with concentrations $(1,2$, and $4 \mu \mathrm{g} / \mu \mathrm{l})$ were prepared in normal saline for biological assay.

\section{Anticoagulant activity assay}

Following manufacturer's information, two parameters PT and aPTT were separately tested to explore at which step of coagulation pathways were inhibited by L. sativa extracts. Commercial heparin $(1 \mu \mathrm{g} / \mu \mathrm{l})$ was used as a positive control for both parameters and regular saline was used as a negative control.

\section{Prothrombin time assay}

In a fusion tube, $25 \mu$ l of normal citrated PPP and $25 \mu \mathrm{l}$ of extract solution was added and incubated at $37^{\circ} \mathrm{C}$ for $2-3$ minutes. Instantly, the time for clot formation (in seconds) was recorded using a stopwatch after the addition of $100 \mu \mathrm{l}$ of PT reagent.
Activated partial thromboplastin time assay

In a fusion tube, $25 \mu \mathrm{l}$ of normal citrated PPP and $25 \mu \mathrm{l}$ of extract solution was added and incubated for 2 minutes at $37^{\circ} \mathrm{C}$. Then $25 \mu \mathrm{l}$ of APTT reagent was added and incubated for 2-3 minutes. By using the stopwatch, the time for clot formation (in seconds) was recorded immediately after the addition of $50 \mu \mathrm{l}$ of $(0.025 \mathrm{M}) \mathrm{CaCl}_{2}$ solution.

\section{Statistical analysis}

The results were expressed as mean \pm S.D with $n=2$ using IBM SPSS statistics 20 . The data were statistically analyzed by one-way ANOVA with Tukey's post hoc test. For the anticoagulant activity experiment, the data were statistically analyzed by one-way repeated measures RM-ANOVA with Bonferroni's post hoc test. The P-value of less than 0.05 was considered as statistically significant.

\section{RESULTS AND DISCUSSION}

\section{Extraction yield}

After employing a cold maceration method, the yields of L. sativa (each part of each variety) dried methanolic extracts were presented in Table I. The extraction yields of $L$. sativa stems were higher than the leaves for both varieties. Since the L. sativa is freshly consumed and rarely cooked, the application of cold maceration as a method of extraction using methanol may be a more suitable choice for extraction. The high yield of methanolic stem extract may be ascribed to the presence of an abundant quantity of sulfated polysaccharides in the stems as observed by (Nie et al., 2017).

\begin{tabular}{|c|c|c|}
\hline Variety & Part & Extraction yield $(\% \mathrm{w} / \mathrm{w})$ \\
\hline Lactuca sativa & Leaves & 3.67 \\
\hline var. longifolia & Stems & 17.35 \\
\hline Lactuca sativa & Leaves & 5.73 \\
\hline var. capitata & Stems & 16.26 \\
\hline
\end{tabular}




\section{Preliminary phytochemical investigation}

The methanolic extracts of L. sativa varieties leave and stem revealed the presence of various bioactive constituents such as carbohydrates, saponins, terpenoids, steroids, flavonoids, coumarins, and mucilage as tabulated in Table II. However, there was a little dissimilarity between the leaves and the stems, i.e. the tannins have been detected only in the leaves.

Table II. Extraction yield of L. sativa methanolic extracts

\begin{tabular}{|c|c|c|c|c|c|}
\hline \multirow{2}{*}{ Phtochemical } & \multirow{2}{*}{ Test } & \multicolumn{2}{|c|}{$\begin{array}{c}\text { Lactuca } \\
\text { sativa var. } \\
\text { longifolia }\end{array}$} & \multicolumn{2}{|c|}{$\begin{array}{c}\text { Lactuca } \\
\text { sativa var. } \\
\text { capitata }\end{array}$} \\
\hline & & ટ્ฮ & कू & ટ્ّ & 苛 \\
\hline \multirow[t]{2}{*}{ Carbohydrates } & $\begin{array}{l}\text { Molisch's } \\
\text { test }\end{array}$ & ++ & ++ & ++ & ++ \\
\hline & $\begin{array}{l}\text { Fehling's } \\
\text { test }\end{array}$ & ++ & ++ & ++ & ++ \\
\hline Saponins & Foaming test & ++ & + & ++ & + \\
\hline Steroids & $\begin{array}{l}\text { Lieberman- } \\
\text { Burchard } \\
\text { test }\end{array}$ & ++ & ++ & ++ & ++ \\
\hline Terpenoids & $\begin{array}{l}\text { Salkowski } \\
\text { tes }\end{array}$ & ++ & ++ & ++ & ++ \\
\hline Flavonoids & $\begin{array}{l}\text { Alkaline } \\
\text { reagent test }\end{array}$ & ++ & ++ & ++ & ++ \\
\hline Tannins & $\begin{array}{l}\text { Ferric } \\
\text { chloride test }\end{array}$ & + & - & + & - \\
\hline Mucilage & $\begin{array}{l}\text { Absolute } \\
\text { alcohol }\end{array}$ & + & ++ & + & ++ \\
\hline Coumarins & $\begin{array}{l}\text { Fluorescence } \\
\text { test }\end{array}$ & + & ++ & + & ++ \\
\hline
\end{tabular}

$(-)$ : Negative result, $(+)$ : Positive result, $(++)$ : Strong positive result

\section{Estimation of nutritional value}

Four components have been measured for the leaves and the stems of both L. sativa varieties and the results are presented in Figure 1. Concerning the findings of crud protein, the leaves of both varieties implied a significant increase $(\mathrm{P}<0.05)$ in the percentage of crude protein in comparison to the stems of each variety. The leaves of $L$. sativa var. longifolia revealed a superior protein content (23.07\%). Crude fat results were very low comparing to other nutrients. The values of the leaves of both varieties were significantly higher $(\mathrm{P}<0.05)$ than the stems. The values of total ash were not significantly different $(\mathrm{P}>$ 0.05) from each other, despite the leaves of $L$. sativa var. capitata showed a little increase amongst other studied powders. Moisture content results were significantly different $(\mathrm{P}<0.05)$ between the leaves and the stems of both varieties. Higher moisture content was observed in the stems of both varieties than the leaves.

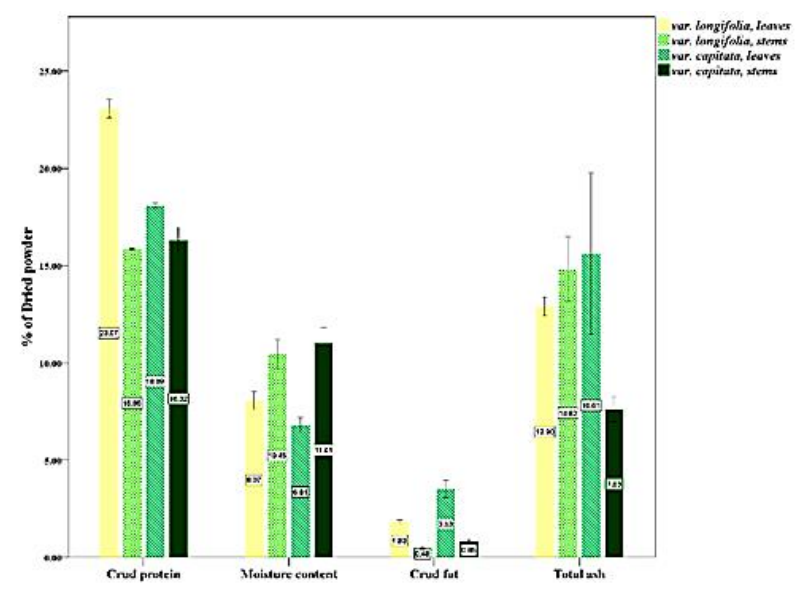

Figure 1. The nutrients percentage of dried powder for each part of L. sativa varieties. Error bars represent SD (n=2)

Relatively, the leaves and the stems of $L$. sativa varieties can be assumed as a good source for vegetable protein, which is necessary for body development and function. The leaves of L. sativa var. longifolia revealed a superior protein content $(23.07 \%)$, which agrees with the observed result $(24.78 \%)$ by Fujihara et al. (2001), who have measured the protein content for other vegetables in addition to $L$. sativa leaves, and the results exhibited that the $L$. sativa has an elevated protein content in relative to Solanum melongena, Daucus carota, Brassica rapa, and Cucurbita maxima. Both parts of L. sativa are considered as a low-fat diet; therefore, they can be recommended for overweight individuals that are seeking weight loss. The value of $L$. sativa var. capitata leaves showed a greater fat content $(3.53 \%)$, which is approaching the observation (4.1\%) that has been reported by Wheeler et al. (1994).

\section{In-vitro analysis of antioxidant activity}

The efficiency of the sample in scavenging the DPPH radicals is expressed by the $\mathrm{IC}_{50}$ value. A small $\mathrm{IC}_{50}$ value implies a high antioxidant activity. A significant difference $(\mathrm{P}<0.05)$ in the $\mathrm{IC}_{50}$ values were found 
between the leaves and the stems of both varieties. Specifically, the leaves of L. sativa var. capitata displayed the lowest $\mathrm{IC}_{50}(2.41 \mathrm{mg} / \mathrm{ml})$ in comparison to the leaves of L. sativa var. longifolia $(3.23 \mathrm{mg} / \mathrm{ml})$. However, there was no significant difference in the stems of both varieties with $(\mathrm{P}>0.05)$, and they displayed higher $\mathrm{IC}_{50}$ values comparing to the leaves. In comparison to the L-ascorbic acid, the resulted $\mathrm{IC}_{50}$ is $(0.01 \mathrm{mg} / \mathrm{ml})$, which is the lowest value among the tested L. sativa extracts; therefore, Lascorbic acid has a significant $(\mathrm{P}<0.05)$ superior antioxidant activity more than other tested extracts Figure 2.

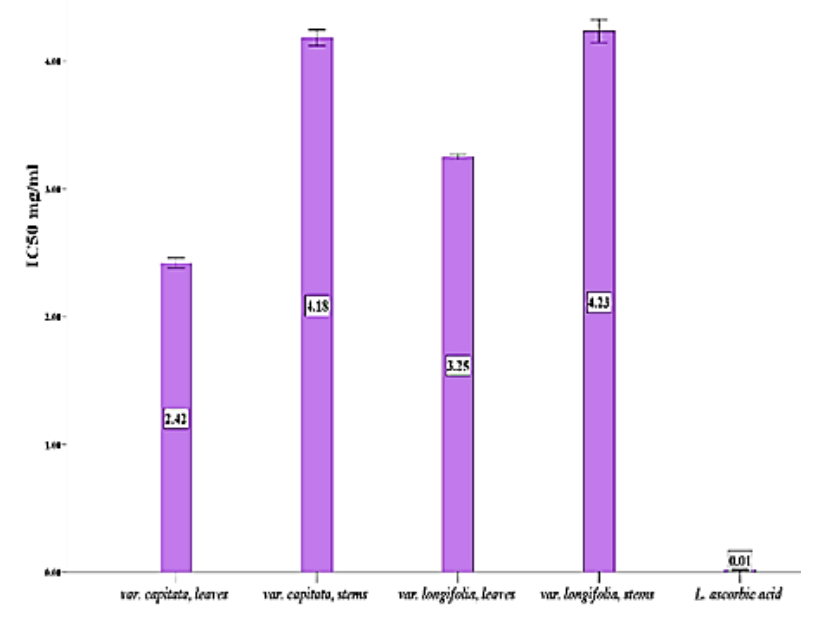

Figure 2. IC $_{50}$ values for each part of L. sativa different varieties and L. ascorbic acid. Error bars represent SD $(n=2)$

The diversity of $L$. sativa phytoconstituents can be considered as a functional food and adjuvant treatment for several chronic diseases as CVDs. Hence, the antioxidant activity of $L$. sativa may be related to the presence of flavonoids, coumarins, and tannins as many studies have reported the strong correlation between these compounds and the high DPPH scavenging activity of L. sativa leaves (Llorach et al., 2008; Liu et al., 2007). In this work, a higher antioxidant activity has been observed in leaves in comparison to the stems. This may be attributed to the presence of polyphenolic compounds (tannins) in the leaves. Tannins act as strong natural antioxidants and a substitute for many synthetic antioxidants (Sung et al., 2012). Under the same conditions of DPPH assay, Gan and Azrina (2016) have measured the $\mathrm{IC}_{50}$ of $70 \%$ aqueous ethanolic extracts of $L$. sativa var. longifolia and L. sativa var. capitata leaves. The resulted values were $(4.48$ and $3.99 \mathrm{mg} / \mathrm{ml})$, respectively, which are approaching those reported in the present work $(3.23 \mathrm{mg} / \mathrm{ml}$ and $2.41 \mathrm{mg} / \mathrm{ml})$ for the leaves methanolic extract for the same varieties. Therefore, the bit dissimilarity in the results may be due to the difference in the solvent of extraction and the phenolic content.

\section{In-vitro analysis of anticoagulant activity}

Coagulation waterfall is mediated by clotting factors, which circulate in blood plasma in an inactive form and are activated in response to any triggers. Coagulation cascade includes two correlating pathways; intrinsic and extrinsic pathways (Triplett, 2000; Palta et al., 2014). Prothrombin time test reflects the extrinsic pathway because the PT reagent composes of calcified thromboplastin, which stimulates the clotting factors that mediate the extrinsic pathway; whereas, the intrinsic pathway can be examined by aPTT test using aPTT reagent, which is consisted of kaolin cephaeline that acts as an activator in presence of calcium ions for intrinsic clotting factors (Jesonbabu et al., 2012). In this study, the leaves and the stems extract of both selected varieties exhibited a significant prolongation of $\mathrm{PT}(\mathrm{P}<0.05 \mathrm{vs}$. NS $=12: 30 \mathrm{~s}$ ). Hence, both the leaves and the extract of the stem of each variety may lead to the reduction of coagulation time. Specifically, Bonferroni's post hoc test revealed that the concentration $4 \mu \mathrm{g} / \mu \mathrm{l}$ has significantly raised the PT ( $\mathrm{P}<0.05$ vs. NS) for both parts of each variety. The leaves extract of L. sativa var. capitata showed the greatest PT value (27.38 s) among other extracts as presented in Figure 3. 


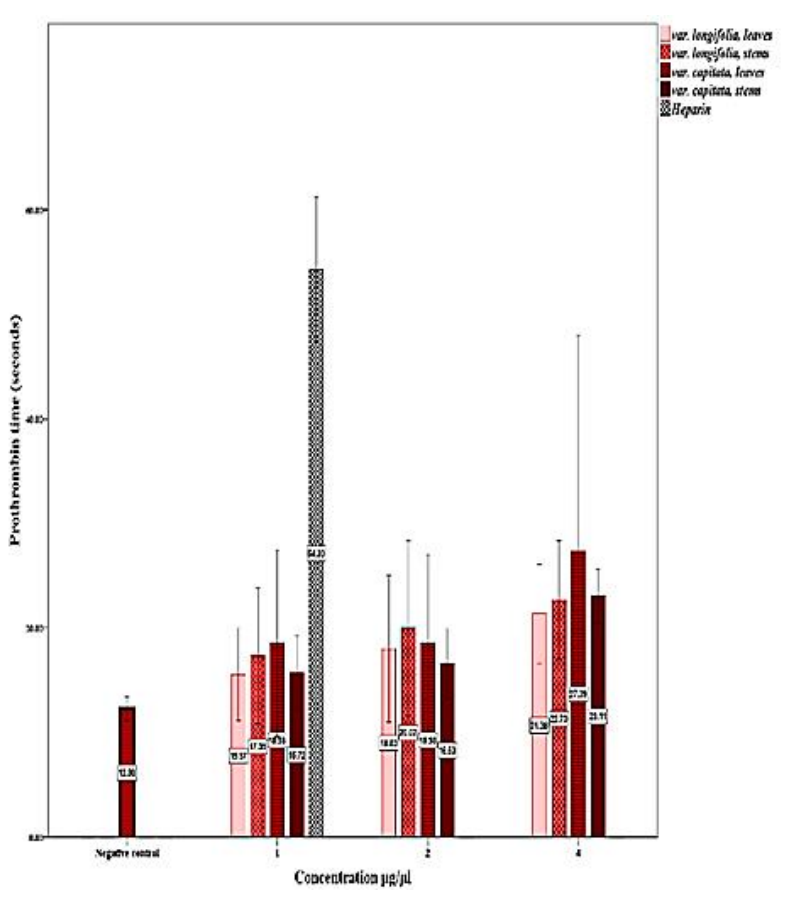

Figure 3. Prothrombin time values comparison among the $L$. sativa methanolic extracts with NS and heparin. Error bars represent the $\mathrm{SD}(\mathrm{n}=4)$

For the aPTT test, the stems extract of both varieties displayed a significant increase in aPTT $(\mathrm{P}<0.05 \mathrm{vs}$. NS= 32:44 s); whereas, the leaves of both varieties have not exhibited any significant elevation in aPTT at the three concentrations ( $\mathrm{P}>0.05$ vs. NS). Only the concentration 4 $\mu \mathrm{g} / \mu \mathrm{l}$ has significantly prolonged the aPTT $(\mathrm{P}<0.05$ vs. NS). The stems L. sativa var. longifolia showed a higher aPTT value (43:19s) than the stems of $L$. sativa var. capitata (40:33 s). The aPTT and PT values of heparin were significantly higher $(\mathrm{P}<0.05)$ than other extracts as illustrated in Figures 3 and 4.

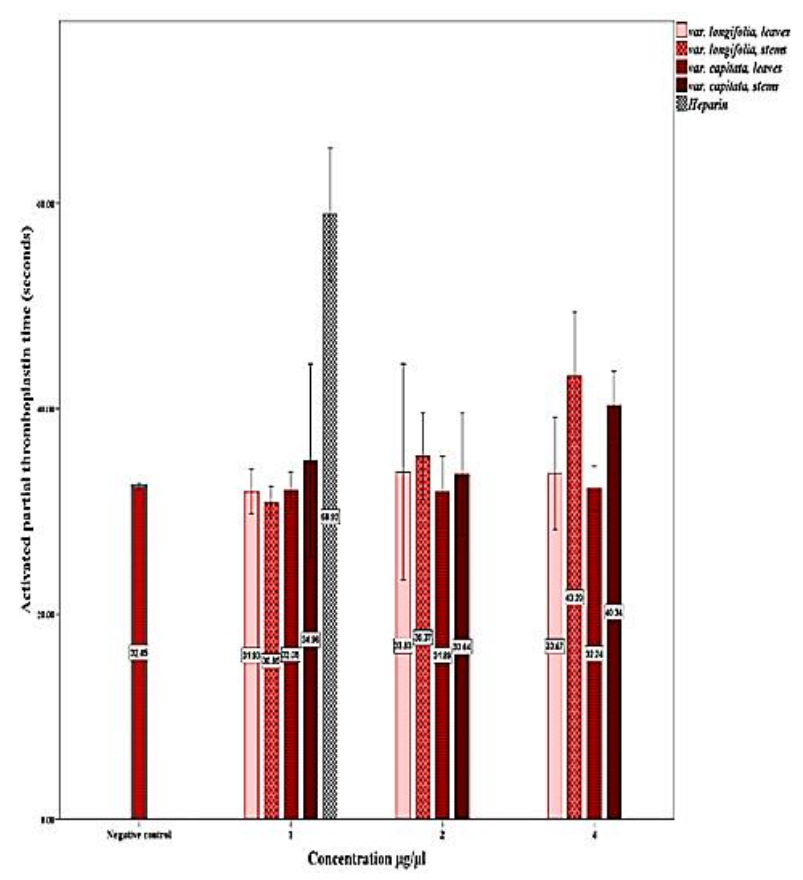

Figure 4. Activated partial thromboplastin time values comparison among the L. sativa methanolic extracts with NS and heparin. Error bars represent the SD $(n=4)$

This research was the first attempt to investigate the in vitro anticoagulant activity of L. sativa on human plasma. Sometimes in vitro activity has not been translated into in vivo activity due to the pharmacokinetic considerations. However, Ismail and Mirza (2015) have conducted an in vivo evaluation of the anticoagulant activity of L. sativa leaves. The results displayed a significant anticoagulant activity of $L$. sativa leaves extract. This in vivo study can improve the accuracy of the present study results from the in vitro assay. Hence, we can rely on the in vitro anticoagulant essay as a model for the evaluation of the anticoagulant activity. The presence of various phytoconstituents L. sativa extracts such as flavonoids, saponins, terpenoids, steroids, and coumarins, which play an integral role in the reduction of coagulation time (Duric et al., 2015; Ashwini \& Asha, 2017; Moghadamtousi et al., 2013). Only the stems of each variety exhibited an effect on the intrinsic pathway by prolongation of aPTT. This may due to the presence of high content of sulfated polysaccharides in the stems of $L$. sativa relative to the leaves (Nie et al., 2017). Sulfated 
polysaccharides have exhibited an effect only on the intrinsic pathway by increasing the aPTT, and they have not displayed any effect on the extrinsic pathway (Rodrigues et al., 2011; Karaki et al., 2013).

\section{CONCLUSION}

From this study, the yield of stem methanol extracts was higher than the yield of leaf for both varieties. Both parts of each variety showed the presence of the same phytochemicals with a slight discrepancy between the leaves and the stems, i.e. tannins were detected only in the leaves. The content of the leaves' nutrients in both varieties showed statistically significantly higher levels of raw protein, raw fat, and fairly total ash compared to the studied stem powders. As regards the DPPH assay, the leaves of both varieties have a statistically significantly higher antioxidant activity than the stems. The stems revealed a statistically significant higher anticoagulant activity than the leaves.

\section{ACKNOWLEDGMENT}

Special appreciation to the University of Tripoli and Food Quality Control Center, Tripoli, Libya, for the opportunity to conduct nutritional value experiments. Equally thanks to Mr. Abduladeem Hedwar, Mr. Khaled Smein, Miss. Amina Osta, and Dr. Abdulrazag Tajuri, for their valuable assisting.

\section{REFERENCES}

Alavi, S.A. (1983). Flora of Libya: Asteraceae, Volume 107. 402-403. Tripoli, Libya: Department of Botany, Al Faateh University.

Araruna, K. \& Carlos, B. (2010). Anti-inflammatory activities of triterpene lactones from Lactuca sativa. Phytopharmacology, 1(1), 1-6.

Ashwini, U. \& Asha, S. (2017). A Preliminary Novel Findings on Invitro Anti-Coagulant Activity of Acalypha Indica Linn Leaf Extracts.
International Journal of Pharmaceutical and Clinical Research, 9(5), 425-429. doi:10.25258/ijpcr.v9i5.8607

Association of Official Agricultural Chemists. (2000). Official Methods of Analysis of AOAC International, $16^{\text {th }}$ edition. Virginia, US: AOAC International.

Association of Official Agricultural Chemists. (1990). Official Methods of Analysis of AOAC International, $15^{\text {th }}$ edition. Virginia, US: AOAC International.

Banu, K.S. \& Cathrine, L. (2015). General Techniques Involved in Phytochemical Analysis. International Journal of Advanced Research in Chemical Science, 2(4), 25-32.

Bhandary, S.K., Kumari, S.N., Bhat, V.S., Sharmila, K.P., \& Bekal, M.P. (2012). Preliminary phytochemical screening of various extracts of Punica granatum peel, whole fruit and seeds. Nitte University Journal of Health Science, 2(4), 3438. doi:10.1055/s-0040-1703609

Bhat, R.S. \& Al-Daihan, S. (2014). Phytochemical constituents and antibacterial activity of some green leafy vegetables. Asian Pacific Journal of Tropical Biomedicine, 4(3), 189-193. doi:10.1016/S2221-1691(14)60230-6

Buttar, H.S., Li, T., \& Ravi, N. (2005). Prevention of cardiovascular diseases: Role of exercise, dietary interventions, obesity and smoking cessation. Experimental and Clinical Cardiology, 10(4), 229-249.

Chen, H., Jin, M., Wang, Y.F., Wang, Y.Q., Meng, L., Li, R., Wang, J.P., Kong, Y., \& Wei, J.F. (2014). Effect of Toona microcarpa Harms Leaf Extract on the Coagulation System. BioMed Research International, 2014, 615363. doi:10.1155/2014/615363

Cordier, W., Cromarty, A.D., Botha, E., \& Steenkamp, V. (2012). Effects of selected South African plant extracts on haemolysis and coagulation. Human and Experimental Toxicology, 31(3), 250257. doi:10.1177/0960327111398675

Cordier, W. \& Steenkamp, V. (2012). Herbal remedies affecting coagulation: a review. Pharmaceutical Biology, $\quad 50(4), \quad 443-452$. doi:10.3109/13880209.2011.611145 
Duric, K., Besovic, E.E.K., Niksic, H., Muratovic, S., \& Sofic, E. (2015). Anticoagulant activity of some Artemisia dracunculus leaf extracts. Bosnian Journal of Basic Medical Sciences, 15(2), 9-14. doi:10.17305/bjbms.2015.384

Edeoga, H.O., Okwu, D.E., \& Mbaebie, B.O. (2005). Phytochemical constituents of some Nigerian medicinal plants. African Journal of Biotechnology, 4(7), 685-688. doi:10.5897/AJB2005.000-3127

Evans, W. (2009). Trease and Evans' Pharmacognosy, 16th Edition. Edinburgh, UK: Elsevier.

Fujihara, S., Kasuga, A., \& Aoyagi, Y. (2001). Nitrogen-toProtein Conversion Factors for Common Vegetables in Japan. Journal of Food Science, 66(3), 412-415. doi:10.1111/j.13652621.2001.tb16119.x

Gan, Y.Z. \& Azrina, A. (2016). Antioxidant properties of selected varieties of lettuce (Lactuca sativa L.) commercially available in Malaysia. International Food Research Journal, 23(6), 23572362.

Han, Y.F., Cao, G.X., Gao, X.J., \& Xia, M. (2010). Isolation and characterisation of the sesquiterpene lactones from Lactuca sativa $L$ var. anagustata. Food Chemistry, 120(4), 1083-1088. doi:10.1016/j.foodchem.2009.11.056

Ismail, H., Dilshad, E., Waheed, M.T., \& Mirza, B. (2017). Transformation of Lettuce with rol ABC Genes: Extracts Show Enhanced Antioxidant, Analgesic, Anti-Inflammatory, Antidepressant, and Anticoagulant Activities in Rats. Applied Biochemistry and Biotechnology, 181, 1179-1198. doi:10.1007/s12010-016-2277-3

Ismail, H. \& Mirza, B. (2015). Evaluation of analgesic, antiinflammatory, anti-depressant and anticoagulant properties of Lactuca sativa (CV. Grand Rapids) plant tissues and cell suspension in rats. BMC Complementary Medicine and Therapies, 15, 199. doi:10.1186/s12906-015-0742-0

Jesonbabu, J.N., Spandana, M., Reddy, M.S, \& Lakshmi, K.A. (2012). A bioactive compound from piper betel with anticoagulant activity. International Journal of Pharmacy and Pharmaceutical Sciences, 4(3), 109-112.
Karaki, N., Sebaaly, C., Chahine, N., Faour, T., Zinchenko, A., Rachid, S., \& Kanaan, H. (2013). The antioxidant and anticoagulant activities of polysaccharides isolated from the brown algae Dictyopteris polypodioides growing on the Lebanese coast. Journal of Applied Pharmaceutical Science, 3(2), 43-51. doi:10.7324/JAPS.2013.30208

Kumar, S., Sandhir, R., \& Ojha, S. (2014). Evaluation of antioxidant activity and total phenol in different varieties of Lantana camara leaves. BMC Research Notes, 7, 560. doi:10.1186/17560500-7-560

Kumarasamy, Y., Byres, M., Cox, P.J., Jaspars, M., Nahar, L., \& Sarker, S.D. (2007). Screening seeds of some Scottish plants for free radical scavenging activity. Phytotherapy Research, 21(7), 615-621. doi:10.1002/ptr.2129

Liu, X., Ardo, S., Bunning, M., Parry, J., Zhou, K., Stushnoff, C., Stoniker, F., Yu, L., \& Kendall, P. (2007). Total phenolic content and DPPH radical scavenging activity of lettuce (Lactuca sativa L.) grown in Colorado. LWT - Food Science and Technology, 40(3), 552-557. doi:10.1016/j.lwt.2005.09.007

Llorach, R., Martínez-Sánchez, A., Tomás-Barberán, F.A., Gil, M.A., \& Ferreres, F. (2008). Characterisation of polyphenols and antioxidant properties of five lettuce varieties and escarole. Food Chemistry, 108(3), 1028-1038. doi:10.1016/j.foodchem.2007.11.032

Michalska, K., Stojakowska, A., Malarz, J., Doležalová, I., Lebedam A., \& Kisiel, W. (2009). Systematic implications of sesquiterpene lactones in Lactuca species. Biochemical Systematics and Ecology, 37(3), doi:10.1016/j.bse.2009.02.001

174-179.

Mir, M.A., Parihar, K., Tabasum, U., \& Kumari, E. (2016). Estimation of alkaloid, saponin and flavonoid, content in various extracts of Crocus sativa. Journal of Medicinal Plants Studies, 4(5), 171-174.

Moghadamtousi, S.Z., Goh, B.H., Chan, C.K., Shabab, T., \& Kadir, H.A. (2013). Biological Activities and Phytochemicals of Swietenia macrophylla King. Molecules, 18(9), 10465-10483. doi:10.3390/molecules180910465

Morsy, N. (2014). Phytochemical analysis of biologically active constituents of medicinal plants. Main 
Group Chemistry, 13(1), 7-21. doi:10.3233/MGC-130117

Mughrbi, H.N. \& Auzi, A.A. (2020). Lactuca sativa Stems as the Source of Bioactive Compounds as well as the Leaves. Journal of Pharmacy and Pharmacology, 8(5), 143-150. doi:10.17265/23282150/2020.05.003

Najafabad, A.M. \& Jamei, R. (2014). Free radical scavenging capacity and antioxidant activity of methanolic and ethanolic extracts of plum (Prunus domestica L.) in both fresh and dried samples. Avicenna Journal of Phytomedicine, 4(5), 343-353.

Ngbede, J., Yakubu, R.A., \& Nyam, D.A. (2008). Phytochemical Screening for Active Compounds in Canarium schweinfurthii (Atile) Leaves from Jos North, Plateau State, Nigeria. Research Journal of Biological Sciences, 3(9), 1076-1078.

Nie, C., Zhu, P., Ma, S., Wang, M., \& Hu, Y. (2018). Purification, characterization and immunomodulatory activity of polysaccharides from stem lettuce. Carbohydrate Polymers, 188, 236-242. doi:10.1016/j.carbpol.2018.02.009

Nie, C., Zhu, P., Wang, M., Ma, S., \& Wei, Z. (2017). Optimization of water-soluble polysaccharides from stem lettuce by response surface methodology and study on its characterization and bioactivities. International Journal of Biological Macromolecules, 105(1), 912923. doi:10.1016/j.ijbiomac.2017.07.125

Palta, S., Saroa, R., \& Palta, A. (2014). Overview of the coagulation system. Indian Journal of Anaesthesia, 58(5), 515-523. doi:10.4103/00195049.144643

Ribas-Agusti, A., Gratacós-Cubarsí, M., Sárraga, C., García-Regueiro, J.A., \& Castellari, M. (2011). Analysis of eleven phenolic compounds including novel p-coumaroyl derivatives in lettuce (Lactuca sativa L.) by ultra-highperformance liquid chromatography with photodiode array and mass spectrometry detection. Phytochemical Analysis, 22(6), 555563. doi:10.1002/pca.1318

Rodrigues, J.A.G., Vanderlei, E.D.S.O., Bessa, E.F., Magalhães, F.D.A., de Paula, R.C.M., Lima, V., \& Benevides, N.M.B. (2011). Anticoagulant activity of a sulfated polysaccharide isolated from the green seaweed Caulerpa cupressoides. Brazilian Archives of Biology and Technology, 54(4), 691-700. doi:10.1590/S151689132011000400007

Singh, D., Singh, P., Gupta, A., Solanki, S., Sharma, E., \& Nema, R. (2012). Qualitative Estimation of the Presence of Bioactive Compound in Centella Asiatica: An Important Medicinal Plant. International Journal of Life Science and Medical Research, 2(1), 5-7. doi:10.5963/LSMR0201002

Sung, S.H., Kim, K.H., Jeon, B.T., Cheong, S.H., Park, J.H., Kim, D.H., Kweon, H.J., \& Moon, S.H. (2012). Antibacterial and antioxidant activities of tannins extracted from agricultural byproducts. Journal of Medicinal Plants Research, 6(15), 3072-3079. doi:10.5897/JMPR11.1575

Triplett, D.A. (2000). Coagulation and bleeding disorders: review and update. Clinical Chemistry, $46(8 \mathrm{pt}$ 2), 1260-1269. doi:10.1093/clinchem/46.8.1260

Wheeler, R.M., Mackowiak, C.L., Sager, J.C., Yorio, N.C., Knott, W.M., \& Berry, W.L. (1994). Growth and gas exchange by lettuce stands in a closed, controlled environment. Journal of the American Society for Horticultural Science, 119(3), 610-615.

Zdravković, J.M., Aćamović-Djoković, G.S., Mladenović, J.D., Pavlović, R.M., \&Zdravković, M.S. (2014). Antioxidant capacity and contents of phenols, ascorbic acid, $\beta$-carotene and lycopene in lettuce. Hemijska industrija, 68(2), 193-198. doi:10.2298/HEMIND130222043Z 